\title{
Neonatal Home Care Practices and Care Seeking Behaviour in Rural Makwanpur of Nepal
}

\author{
Baral KP' ${ }^{1}$, Hunter KL ${ }^{2}$, Poudel S1, Koirala S ${ }^{1}$, Rezai T ${ }^{3}$, Upadhyay SK ${ }^{1}$ \\ ${ }^{1}$ Patan Academy of Health Sciences, Lalitpur, Nepal; ${ }^{2}$ Simon Fraser University, Canada; ${ }^{3}$ Stanford University, USA
}

Received: 4-Mar-2017; Accepted: 10-May-2017

\begin{abstract}
Aims: This study assesses the state of newborn home-care practices and care-seeking behaviors among the recently delivered mothers to better inform the behavior change communication efforts for effective implementation of the program.

Methods: A descriptive study was conducted in two village development committees of Makwanpur district from June to July 2011. A total of 214 women, residing for six months or more in study areas and delivered within past one year, were interviewed using questionnaires designed to collect quantitative and qualitative data.

Results: Eighty eight percent of the respondents practiced exclusive breastfeeding, $44 \%$ dried and wrapped their newborn within the first five minutes following delivery and $84 \%$ used a clean instrument to cut the umbilicus. Ninety-five percent of mother accessed antenatal care from a skilled health provider, $77 \%$ of mothers completed four antenatal care visits and only $13 \%$ of mothers accessed postnatal care. The first place the mothers would go for seeking care for the neonates was the Primary Health Care Center (54\%) followed by the traditional practitioners $(20 \%)$ and private clinics (6\%). The low quality of services at Primary Health Care Center was the most commonly cited barrier to care-seeking (22\%) followed by staff unavailability, behaviour and poor counselling.
\end{abstract}

Conclusions: Effective implementation of community-based integrated newborn care program will require engaging stakeholders in both short-term behaviour change communication strategies and long-term commitments to improving quality of care.

Keywords: behavior change and communication, community-based integrated newborn care program, newborn care-seeking behaviors, newborn home-care practices

DOI: http://dx.doi.org/10.3126/njog.v12i1.18980

\section{INTRODUCTION}

The neonatal death stands high at $61 \%$ of total deaths among under-five children and the mortality rate has stagnated at 33 deaths per 1,000 live births during 2005-2010 in Nepal. ${ }^{1}$ Neonatal mortality is more $(36 / 1000)$ in rural regions than that of urban areas $(25 / 1000){ }^{1}$

Evidences suggest that promoting essential newborn care practices in the home, specifically related to breastfeeding, cord care, thermal care and hygiene plays a central role in reducing neonatal morbidity and mortality. ${ }^{2,3-8}$ Promoting neonatal care practices in home is especially important in rural Nepal where $67 \%$ of mothers deliver at home and $68 \%$ deliver without a skilled provider. ${ }^{1}$

\section{CORRESPONDENCE}

Dr Kedar Prasad Baral

Department of Community Health Sciences, Patan Academy of Health Sciences

Lagankhel-5, Lalitpur, Nepal

Phone: +977-9851145081, Email: kedarbaral@pahs.edu.np
The Ministry of Health and Population (MoHP), Nepal in 2009 initiated a pilot Community-Based Integrated Newborn Care Program (CB-NCP) in ten districts including a central hill district of Makwanpur. ${ }^{9-10}$ This study assesses the state of newborn home-care practices and care-seeking behaviors of the recently delivered mothers to better inform the behavior change communication (BCC) efforts for effective implementation of CB-NCP.

\section{METHODS}

A descriptive study was conducted in Bhimphedi and Daman village development committees (VDCs)- smallest geopolitical units of the country each comprising 9 wards- of Makwanpur district. All women who had resided for six months or more in the study areas and had given birth within a year of the survey start date were eligible respondents. A total of 237 respondents were identified with the assistance of local health and social workers. One woman declined participation and 22 women were away from the VDCs during the study. A total of 214 mothers, 97 from Bhimphedi and 117 from Daman, were surveyed from June to July 2011. 
Research priorities outlined in the 2004 National Neonatal Health Strategy ${ }^{11}$ and the 2006 Nepal Demographic Health Survey ${ }^{12}$ data were used to guide the development of quantitative and qualitative study tools. Survey questionnaire and interview checklist were developed based on literature review on neonatal health in rural settings, including optimal neonatal care practices outlined by the World Health Organization and Saving Newborn Lives Initiative. ${ }^{13,14}$ Tools were pilot tested in Bajrabarahi VDC of Makwanpur with women meeting the selection criteria and finalized based on revisions/recommendations of the investigators, Patan Academy of Health Sciences (PAHS) faculty members and Daman Primary Health Care Center (PHCC) in-charge.

Data was collected simultaneously in both VDCs using the same tool and techniques. All interviews, each lasting about 45 minutes, were taken at respondent's own home. Foreign researchers were accompanied by interpreters. Data analysis was done using IBM SPSS Statistics 19. Ethical approval was obtained from the Nepal Health Research Council and the Research Ethics Board at Simon Fraser University.

\section{RESULTS}

The average age of respondent mothers was 24 years $(\mathrm{SD} \pm 4.8)$ and ranged from 16 to 41 years. The majority of mothers were literate (61\%). Fortyone percent of mothers delivered at home, primarily assisted by family and friends. Ninety-five percent of mothers accessed antenatal care (ANC), of which $77 \%$ received ANC at least four times. Conversely, $87 \%$ of mothers did not access postnatal care (PNC). Additional socioeconomic and health indicators are summarized in Table 1.

Table 1: Comparison of Bhimphedi and Daman Village Development Committees. (Figures are in percentages).

\begin{tabular}{|c|c|c|c|}
\hline Development and Health Indicators & Bhimphedi (n=97) & Daman $(n=117)$ & Overall $(n=214)$ \\
\hline \multicolumn{4}{|l|}{ Household amenities or items } \\
\hline Electricity & 91.8 & 91.5 & 91.6 \\
\hline Toilet facility- Yes & 94.8 & 82.6 & 82.2 \\
\hline No & 5.2 & 17.4 & 17.8 \\
\hline Radio & 71.1 & 72.6 & 72 \\
\hline Mobile Phone & 91.8 & 91.5 & 91.6 \\
\hline \multicolumn{4}{|l|}{ Mother literacy } \\
\hline Illiterate & 39.2 & 19.7 & 28.5 \\
\hline Literate, no schooling & 6.2 & 13.7 & 10.3 \\
\hline Literate, primary (Grades 1-5) & 17.5 & 15.4 & 16.4 \\
\hline Literate, secondary and above (Grades 6-12) & 37.1 & 50.4 & 44.4 \\
\hline \multicolumn{4}{|l|}{ Delivery location } \\
\hline Health Facility & 63.9 & 54.7 & 59.3 \\
\hline Home & 36.1 & 44.4 & 40.7 \\
\hline \multicolumn{4}{|l|}{ Assistance at delivery } \\
\hline Skilled $^{\mathrm{a}}$ & 63.9 & 64 & 58.9 \\
\hline Family, friends, neighbors & 34 & 27.4 & 30.4 \\
\hline Others & 2.1 & 8.6 & 10.7 \\
\hline \multicolumn{4}{|l|}{ Health Services } \\
\hline Received any antenatal care & 91.8 & 98.3 & 95.3 \\
\hline Received regular antenatal care ( $\geq 4$ visits) & 76.3 & 76.9 & 76.7 \\
\hline Mother received postpartum care ${ }^{b}$ & 28.9 & 23.9 & 26.2 \\
\hline Neonate received postnatal care ${ }^{\mathrm{c}}$ & 17.5 & 9.4 & 13.1 \\
\hline \multicolumn{4}{|c|}{ aDefined in this study as any ANM-assisted delivery, or a delivery in a facility assisted by a doctor. } \\
\hline \multicolumn{4}{|c|}{ boes not include checks that happened at the hospital on the day of delivery } \\
\hline \multicolumn{4}{|c|}{ 'Does not include checks that happened at the hospital on the day of delivery } \\
\hline
\end{tabular}


Ninety-nine percent of women stated they were regularly breastfeeding at the time of survey. Fiftynine percent of respondents reported exclusive breastfeeding for the first six months. -Prelacteal feeds were administered by $14 \%$ of respondents. Sixtyfour percent of mother initiated breastfeeding within the first hour following delivery and 28\% began breastfeeding one to eight hours following delivery. Fourteen percent of women in study discarded the colostrum.

Forty four percent of mothers recalled drying and wrapping the newborn within the first 5 minutes and
$27 \%$ within the first 15 minutes following the birth Fourteen percent of newborns were bathed within the first hour following delivery while $29 \%$ waited one day and $46 \%$ waited two or more days. A new or boiled razor blade was used to cut the cord in $76 \%$ of home deliveries. Sixteen percent used 'unclean' instruments to cut the cord while $8 \%$ applied nonantiseptic substances such as oil and powder. Findings relating to feeding practices, thermal care and cord care are summarized in Table 2.

Table 2: Neonatal home care practices in Bhimphedi and Daman VDCs in percentages

\begin{tabular}{|c|c|c|c|}
\hline Home Care Practices & Bhimphedi & Daman & Overall \\
\hline Feeding Practices & $(n=97)$ & $(n=117)$ & $(n=214)$ \\
\hline Immediate breastfeeding (within $1 \mathrm{~h}$ ) & 67 & 60.7 & 63.6 \\
\hline Breastfed 1 to $8 \mathrm{~h}$ & 23.7 & 31.6 & 28 \\
\hline Colostrum ${ }^{\mathrm{a}}$ discarded & 17.5 & 11.1 & 14 \\
\hline Given anything to drink prior to breastfeeding & 8.2 & 18.8 & 14 \\
\hline Exclusive breastfeeding first 6 months- Yes & 66 & 53.8 & 59.3 \\
\hline No & 34 & 80.3 & 40.7 \\
\hline Cord Care & $(n=35)$ & $(\mathrm{n}=52)$ & $(\mathrm{n}=87)$ \\
\hline \multicolumn{4}{|l|}{ Instrument used to cut cord at home } \\
\hline New or boiled razor blade & 65.8 & 82.7 & 75.9 \\
\hline Unclean hashiya (farming tool) or razor ${ }^{\mathrm{b}}$ & 31.4 & 5.7 & 16 \\
\hline \multicolumn{4}{|l|}{ Substance applied to cord } \\
\hline Oil & 7.2 & 7.7 & 7.5 \\
\hline Powder & 0 & 0.9 & 0.5 \\
\hline Thermal Control & $(n=97)$ & $(\mathrm{n}=117)$ & $(n=214)$ \\
\hline \multicolumn{4}{|l|}{ Drying and wrapping after birth } \\
\hline Within 5 min & 66 & 26.5 & 44.4 \\
\hline Within $15 \mathrm{~min}$ & 10.3 & 40.2 & 26.6 \\
\hline Within $30 \mathrm{~min}$ & 4.1 & 8.5 & 6.5 \\
\hline Within $1 \mathrm{~h}$ & 1 & 4.3 & 2.8 \\
\hline Was not dried & 14.4 & 9.4 & 11.7 \\
\hline Do not know & 4.1 & 10.3 & 7.5 \\
\hline Bathing after birth & $(\mathrm{n}=97)$ & $(\mathrm{n}=117)$ & $(n=214)$ \\
\hline Within $30 \mathrm{~min}$ & 6.2 & 4.3 & 5.1 \\
\hline $30 \mathrm{~min}-1 \mathrm{hr}$. & 9.3 & 9.4 & 9.3 \\
\hline Same day & 4.1 & 10.3 & 7.5 \\
\hline Next day & 27.8 & 30.8 & 29.4 \\
\hline$\geq 2$ days $^{\mathrm{c}}$ & 52.6 & 40.2 & 45.8 \\
\hline Do not know & 0 & 5.1 & 2.8 \\
\hline \multicolumn{4}{|c|}{ 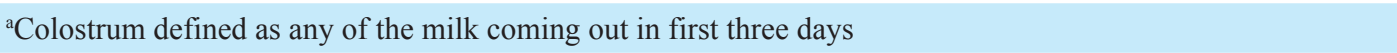 } \\
\hline \multicolumn{4}{|c|}{$\begin{array}{l}\text { bRazor blade already in home, not specifically purchased for birth (new razor blade being one bought at market } \\
\text { specifically for birth) }\end{array}$} \\
\hline \multicolumn{4}{|c|}{ 'Responses ranged from 2 days to 1 month } \\
\hline
\end{tabular}


Fifty-nine percent of mothers delivered in a health facility. Out of 306 recalled cases of neonatal illnesses, $73 \%$ led respondents to seek care from various providers. Fifty-four percent of respondents who sought care went to the PHCC while $20 \%$ sought care at a private clinic. Use of traditional practitioners (Dhami/Jhakri) was found to be similar at $20 \%$ between the two VDCs. Twenty percent of respondents who sought care went on the same day signs of illness emerged. Findings demonstrated that respondents in Bhimphedi delayed seeking care to a greater extent than those from Daman. These findings are summarized in Table 3.

Table 3: Care-seeking behavior for illness during the neonatal period in percentages

\begin{tabular}{|c|c|c|c|}
\hline & Bhimphedi & Daman & Overall \\
\hline Total recalled cases of neonatal illness & $(n=128)$ & $(n=178)$ & $(n=306)$ \\
\hline Sought care for illness & 71.7 & 74.7 & 73.2 \\
\hline Place of consultation & $(n=91)$ & $(n=133)$ & $(n=224)$ \\
\hline PHCC & 58.2 & 50.4 & 53.6 \\
\hline Private Clinic ${ }^{\mathrm{a}}$ & 16.5 & 22.6 & 20.1 \\
\hline Traditional Practitioner (Dhami/Jhakri) & 11 & 9.8 & 10.3 \\
\hline Pharmacy & 1.1 & 15.8 & 9.8 \\
\hline Hospital & 11 & 1.5 & 5.4 \\
\hline Delay in care-seeking & $(\mathrm{n}=91)$ & $(n=133)$ & $(n=224)$ \\
\hline Same Day & 8.8 & 27.1 & 19.6 \\
\hline Next day & 33 & 41.4 & 37.9 \\
\hline 2 Days & 31.9 & 15.8 & 22.3 \\
\hline$\geq 3$ Days & 26.4 & 12.8 & 18.3 \\
\hline
\end{tabular}

Regarding the questions on barriers to care-seeking, a range of responses were provided. Accordingly, the quality of services at the PHCC was the most widespread complaint (22\%) and was a more common complaint in Bhimphedi (31\%) compared to Daman (14\%). Other reasons cited were the unavailability of staff, poor staff behaviour and lack of counselling during visits. Distance was cited as an issue in Bhimphedi (12\%) in comparison with Daman (3\%). The average time required to get to PHCC by foot was 59.7 minutes $(\mathrm{SD} \pm 48.7)$ in Bhimphedi and 36.0 minutes $(\mathrm{SD} \pm 33.1)$ in Daman.

\section{DISCUSSION}

The benefits of breastfeeding in newborn growth and development are widely recognized in the literature. ${ }^{4,13,14}$ High numbers of mothers from study areas reported exclusive breastfeeding during the neonatal period (88\%) as compared to only $24.4 \%$ reported by another study done in Nepal. ${ }^{5}$ Prelacteal feeding causes increased risk of illness and interferes with the establishment of breastfeeding. ${ }^{15}$ It was significantly lower in study areas (14\%) than the national average $(37 \%){ }^{1}$
Early initiation of breastfeeding is considered an important factor for preventing hypothermia and promoting colostrum feeding. ${ }^{15,16}$ Sixty four percent of study-area mothers initiated breastfeeding within the first hour, almost the same reported earlier (63\%) by another study done in Makwanpur. ${ }^{8}$ Discarding the colostrum, the first milk expressed from the breast, is highly discouraged due to its immunologically protective properties for newborns. ${ }^{17,18}$ Only $14 \%$ of mothers reported discarding colostrum, much lower than that reported by earlier study (45\%) in Makwanpur. ${ }^{7}$ Overall, it appears that the prevalence of recommended breastfeeding practices is higher in study population as compared to previous studies.

Likewise, the majority of mothers in this study demonstrated recommended neonatal care practices of immediate drying and delayed bathing. Seventy one percent of babies were dried within the first 15 minutes following delivery as compared to $59 \%$ reported by NDHS 2011. ${ }^{1}$ Only 14\% of respondents bathed the newborn within an hour of delivery as compared to $50 \%$ reported by NDHS $2011 .^{1}$ Though the practice of warming the room following delivery 
was not explored in this study, previous studies suggested this practice being relatively common in Nepal. ${ }^{5,7}$

Use of new or boiled blade in cutting umbilical cord of home deliveries was slightly lower (76\%) than that reported by NDHS 2011 (82\%). ${ }^{1}$ Though optimal cord cutting practice was found to be prevalent, use of 'unclean' farming instruments like sickle and blades in $16 \%$ of home delivery is problematic. Improving access to and use of sterile razor blades for cord cutting through the distribution of clean home delivery kits (CHDKs) could help as shown by a study done in Nepal. ${ }^{5}$ A high proportion of neonates did not have their health checked within 7 days of delivery $(87 \%)$, contrary to the recommended three check-ups following delivery. ${ }^{1}$

Respondent mothers recalled the PHCC as the preferred provider of care for their sick baby (20\%) followed by the traditional practitioner $(20 \%)$ and private clinics $(6 \%)$. It became apparent that multiple providers would be accessed to "maintain satisfaction" as told by one respondent: "To maintain satisfaction, I will first go to the PHCC. At night, I will then go to the traditional healer for mental satisfaction. I will do this especially if the health facility is not open." Another woman similarly described the range of services she would consider accessing: "I would go to the PHC first, and then the hospital and finally I would go to the traditional healer."

In Daman, $15 \%$ of respondents expressed at least one barrier to accessing the PHCC, much lower than that expressed by Bhimphedi's respondents (44\%) who identified one or more barriers. These differences may be because of the PHCC in Daman was consistently staffed by doctors and medical students in addition to Senior Auxiliary Health Workers (SrAHW) and Auxiliary Nurse Midwives (ANM) as noted from observation and community accounts. A single SrAHW, an ANM and a Health Assistant were the sole health staffs present in Bhimphedi during the study period.

The behaviour of health workers was a common concern repeated by respondents. One woman in Bhimphedi emphasized that the staff did not care about patients stating "the doctor is never at the PHC, there is no doctor. No good staffs are available at the PHC." Another woman revealed: "I feel sad when I go to the PHC because they cannot do anything when I get there". Similar findings were reported by a previous study done in Makwanpur. ${ }^{19}$ Lack of basic medicines, poor quality of services and the perception that only minor ailments could be treated were cited as issues with government health services. Likewise the issue of distance and cost were also highlighted by a Senior Health Worker at Bhimphedi: “........ It is easy to access traditional healers. It is difficult for people to walk 3 to 4 hours to the doctor and they feel that the health institutions are all expensive and costly....In a ward there is one FCHV while there are many traditional healers."

Female Community Health Volunteers (FCHVs) play an important role in delivering health care in Nepal. Bhimphedi's SrAHW highlights the added responsibility the new programs like $\mathrm{CB}-\mathrm{NCP}$ places on FCHVs: “.... They [FCHVs] are involved in many organizations. They are just involved in so many tasks so they are not able to give their $100 \%$ in all tasks". In recounting the recent death of a neonate due to infection, the FCHV illustrated the limitations to what she could accomplish: "Six days after delivery, I went to the home after hearing from other people the newborn was suffering from infection. I suggested they should go to a health facility but they would not. The family did not think it was necessary. The baby's chest was also infected and the umbilical cord was infected. The family had cut the cord with a hasiya and did no tie the cord. The baby died 14 days following delivery. If the family does not want to go [to the PHC], I cannot do anything."

\section{CONCLUSIONS}

A significant proportion of mothers in study areas are already engaged in optimal neonatal care practices in the home and promoting contextually appropriate BCC strategies may help improve neonatal survival. The continued use of unclean instruments to cut the cord following home deliveries should be addressed to reduce potential risk of deaths from umbilicus infection.

FCHVs appear to be the most well positioned to deliver BCC messages as peer educators but they are already over burdened and under supported. Involving women's groups in participatory learning and action surrounding neonatal health may help draw more community women into it.

The quality of care being provided at the PHCC needs to be improved with an adequate mix of better 
trained staff and facilities better equipped with resources. More thorough understanding of a range of socioeconomic factors shaping neonatal health outcomes and the mothers' ability to provide optimal care will be important in generating comprehensive health policies and programs for effective implementation of the program. Any sustained improvements in neonatal health will also require engaging stakeholders in both short-term BCC strategies and long-term commitments to improving infrastructure and the socioeconomic determinants of health.

Conflict of Interest: None to declare.

\section{REFERENCES}

1. Ministry of Health \& Population, New Era, ICF Macro, USAID. Nepal Demographic and Health Survey 2011 Kathmandu: Ministry of Health and Population;2012.

2. Darmstadt GL, Bhutta ZA, Cousens S, Adam T, Walker N, De Bernis L. Lancet Neonatal Survival Steering Team. Evidencebased, cost-effective interventions: how many newborn babies can we save? The Lancet. 2005;365:977-88

3. Blencowe $\mathrm{H}$, Cousens S.: Addressing the challenge of neonatal mortality. Trop Med Int Health. 2013;18(3):303-12.

4. Bhutta ZA, Darmstadt GL, Hasan BS, Haws RA. Community based interventions for improving perinatal and neonatal health outcomes in developing countries: a review of the evidence. Pediatr. 2005;115(2):519-617.

5. Karas DJ, Mullany LC, Katz J, Khatry SK, LeClerq SC, Darmstadt GL, et al. Home care practices for newborns in rural southern nepal during the first 2 weeks of life. J Trop Pediatr. 2011;58 (3): 200-7.

6. Kumar V, Mohanty S, Kumar A, Misra RP, Santosham M, Awasthi S, et al. Effect of community-based behaviour change management on neonatal mortality in Shivgarh, Uttar Pradesh, India: a cluster-randomised controlled trial. The Lancet. 2008;372(9644):1151-62.

7. Osrin D, Tumbahangphe KM, Shrestha D, Mesko N, Shrestha BP, Manandhar MK, et al. Cross sectional community baesd study of care of newborn infants in Nepal. BMJ. 2002; ;325(7372):1063-8

8. Lassi ZS, Haider BA, Bhutta ZA. Community-based intervention packages for reducing maternal and neonatal morbidity and mortality and improving neonatal outcomes. Cochrane Database Syst Rev. 2010 Jan 1;11(11).

9. Pradhan YV, Upreti SR, KC NP, KC A, Khadka N, Syed U, et al. Newborn survival in Nepal: a decade of change and future implications. Health Policy and Planning.2012;27:57-71.

10. Smith SL, Neupane S. Factors in health initiative success: learning from Nepal's newborn survival initiative. Soc Sci Med. 2011;72(4):568-75.
11. Ministry of Health. National Neonatal Health Strategy. Kathmandu, Nepal: Ministry of Health; 2004.

12. Ministry of Health and Population (MOHP) [Nepal], New ERA, Macro International Inc: Nepal Demographic and Health Survey 2006. Kathmandu: Ministry of Health and Population, New ERA and Macro International Inc; 2007

13. Beck D, Ganges F, Goldman S, Long P. Care of the Newborn: Reference Manual. Washington: Save the Children Federation. 2004. (available at http://www.chd.gov.np/downloads/Care of_the_Newborn_Reference_Manual_2004.pdf)

14. World Health Organization. Integrated Management of Pregnancy and Childbirth: pregnancy, childbirth, postpartum and newborn care. A guide for essential practice ( $1^{\text {st }}$ Edition). Geneva: World Health Organization. 2006. ( $3^{\text {rd }}$ edition of 2015 available at http://www.who.int/maternal child adolescent/ documents/imca-essential-practice-guide/en/)

15. Rogers NL, Abdi J, Moore D, Nd'iangui S, Smith LJ, Carlson AJ, et al. Colostrum avoidance, prelacteal feeding and late breast-feeding initiation in rural northern Ethiopia. Public Health Nutr. 2011;14(11):2029-36.

16. Mullany LC, Katz J, Khatry SK, LeClerq SC, Darmstadt GL, Tielsch JM. Neonatal hypothermia and associated risk factors among newborns in southern Nepal. BMC Med. 2010;8:43.

17. Kent JC. How breastfeeding works. J Midwifery Womens Health. 2007;52:564-70.

18. Labbok MH, Clark D, Goldman AS. Breastfeeding: maintaining an irreplaceable immunological resource. Nat Rev Immunol. 2004;(4):565-72

19. Mesko N, Osrin D, Tamang S, Shrestha BP, Manandhar $\mathrm{DS}$, Manandhar M, et al. Care for perinatal illness in rural Nepal: a descriptive study with cross-sectional and qualitative components. BMC Int Health Hum Rights. 2003;3:3-14 